\title{
Postpartum Maternal Morbidity Requiring Hospital Admission in A Teaching Hospital: A Descriptive Cross-sectional Study
}

\author{
Pravin Shrestha, ${ }^{1}$ Vibha Mahato, ${ }^{1}$ Smita Shrestha Karmacharya ${ }^{2}$ \\ 'Department of Obstetrics and Gynecology, Manipal College of Medical Sciences, Pokhara, Nepal, \\ ${ }^{2}$ Nobel College, Sinamangal, Kathmandu, Nepal.
}

\section{ABSTRACT}

Introduction: Major concern shifts from mother to newborn in postnatal period. Postpartum complications contribute to a lot of maternal morbidity and mortality. This study aims to determine the prevalence of morbidities in women following delivery at Manipal Teaching Hospital so as to identify and improve maternal quality care.

Methods: This is a descriptive cross-sectional study conducted at department of Obstetrics and Gynaecology, Manipal Teaching Hospital from September 2018 to March 2020 after ethical approval from the institutional review committee with reference number 1296. All the women presenting to the department during the study period were included in the study. Women who were admitted to accompany and nurse their babies for neonatal problems were excluded.Point estimate at $95 \%$ Confidence Interval was calculated along with frequency and proportion for binary data. Data were entered in Excel and analysed in SPSS.

Results: Among 3510 cases, 104 women were admitted with various postpartum morbidities. The prevalenceof postpartum morbidity was found to be $104(2.96 \%)$ at 95\% Confidence Interval (2.67$3.25)$. Puerperal sepsis was diagnosed in $23(22.11 \%)$, preeclampsia in $20(19.23 \%)$ eclampsia in 14 $(13.46 \%)$ and haemorrhage in $14(13.46 \%)$ respectively. Majority of patients, $83.65 \%$ belonged to age group of $20-34$ years. Nine patients $(8.65 \%)$ were teenage mothers.

Conclusions: Puerperal sepsis, preeclampsia, eclampsia and haemorrhage were the major postpartum complications requiring admissions in hospital.

Keywords: hospital admission; maternal morbidity; postpartum.

\section{INTRODUCTION}

Postnatal care is an important part of maternal care as life-threatening complications can occur in the postpartum period. Reducing maternal mortality is a priority agenda of the national and international community as evidenced by the great interest in the Millennium Development Goal (MDG). ${ }^{1}$ In both developing and developed countries $>60 \%$ of maternal deaths occurred in the postpartum period. ${ }^{2}$

According to Nepal demographic health survey, only about $45 \%$ of Nepali women receive postnatal care in the first seven days after delivery. ${ }^{3}$ The incidence of maternal readmission for postpartum morbidity was $1.25 \%$, infectious morbidity being the commonest one. ${ }^{4}$

Maternal morbidity is extensive and under-recognised after delivery. How often these complications occur and when women seek health care is not very well documented. In present study an attempt has been

Correspondence: Dr. Pravin Shrestha, Department of Obstetrics and Gynecology, Manipal College of Medical Sciences, Pokhara, Nepal. Email: pravinstha3@gmail.com, Phone: +9779846111847. 
Shrestha et al. Postpartum Maternal Morbidity Requiring Hospital Admission in A Teaching Hospital: A Descriptive...

made to determine the prevalence of morbidities in postpartum period so as to identify points of intervention for quality improvement in maternal care.

\section{METHODS}

This is a descriptive cross-sectional study conducted in the department of Obstetrics and Gynaecology Manipal Teaching Hospital, Pokhara, Nepal from September 2018 to March 2020. The study was conducted after ethical approval from the institutional review committee with reference number 1296 and consent from patients.

The WHO definition of the postpartum period as beginning one hour after the delivery of placenta continuing till six weeks after the birth of the baby, ${ }^{5}$ was used as the time period for inclusion criteria in this study. All women (3510) presenting to the department of Obstetrics and Gynaecology during the study period were included in the study (census sampling). All patients, either delivered in the study hospital or delivered elsewhere admitted with postpartum morbidity were included. Patients who were admitted just to accompany and nurse their babies for neonatal problems were excluded. The study mainly focussed on types of morbidities, postpartum day of admission and duration of hospital stay.

The data collected were recorded in a predesigned proforma and entered in excel sheet. SPSS (Statistical package for social science 16) was used for calculation and tabulation of data. The final results were discussed and conclusion was derived.

\section{RESULTS}

A total of 104 women presented with various postpartum morbiditiesduring the study period. Total obstetric admissions were 3510 during the study period. The prevalence of postpartum admission was $2.96 \%$ at 95\% Confidence Interval (2.67-3.25). The age ranges from 16 to 40 years with a mean of 26.31(SD 5.3). Majority of patients, $83.65 \%$ belonged to age group of $20-34$ years. Nine patients $(8.65 \%)$ were teenage mothers. Fifty seven (54.80\%) patients admitted with postpartum morbidity had caesarean delivery as shown in (Table 1).

\begin{tabular}{|ll|}
\hline $\begin{array}{l}\text { Table 1. Demographic characteristics and health } \\
\text { variables influencing postpartum morbidity }(\mathbf{n}=104) .\end{array}$ \\
\hline $\begin{array}{l}\text { Variable } \\
\text { Age of the mother (years) }\end{array}$ \\
$<20$ \\
$20-34$ & $9(8.65)$ \\
$>34$ & $87(83.65)$ \\
Period of gestation & $8(7.69)$ \\
$<37$ weeks & $10(9.61)$ \\
$\geq 37$ weeks & $94(90.38)$ \\
Parity & \\
Primipara & $61(58.6)$ \\
Multipara & $43(41.3)$ \\
Mode of delivery & \\
Vaginal & $47(45.1)$ \\
Caesarean section & $57(54.8)$ \\
\hline
\end{tabular}

Twelve women $(11.53 \%)$ were admitted within two days of delivery, $49(47.11 \%)$ in $2-7$ days and 43 (41.34\%) after 7 days for various postpartum morbidity. The duration of hospital stay in this study was less than 7 days in $87(83.65 \%)$ patients and more than 7 days for $17(16.34 \%)$ patients. The average duration of hospital stay was 5.98 days (range 2-18).

Puerperal sepsis was diagnosed in 23 (22.11\%) patients, preeclampsia in $20(19.23 \%)$ patients and eclampsia in $14(13.46 \%)$ patients. Six among them had delivered in the study hospital and eight patients were referred. Fourteen $(13.46 \%)$ patients presented with postpartum haemorrhage. Out of total 14 patients, 6 patients had surgical evacuation, one patient underwent hysterectomy for placenta accreta and others were managed conservatively. In this study 8 patients $(7.69 \%)$ had urinary tract infection, of them 3 presented with retention of urine.

Seven $(6.73 \%)$ patients presented with other complications which included postpartum cardiomyopathy in 2 patients $(1.92 \%)$, paroxysomal supraventricular tachycardia (PSVT) in 1 (0.96\%) patient (who were managed in ICU with cardiology team), organic psychosis in $1(0.96 \%)$ patient, rectus sheath hematoma in $1(0.96 \%)$ patient (who underwent exploration) and $2(1.92 \%)$ patients with abdominal distension who were managed conservatively. Distribution of postpartum morbidity booked in study 


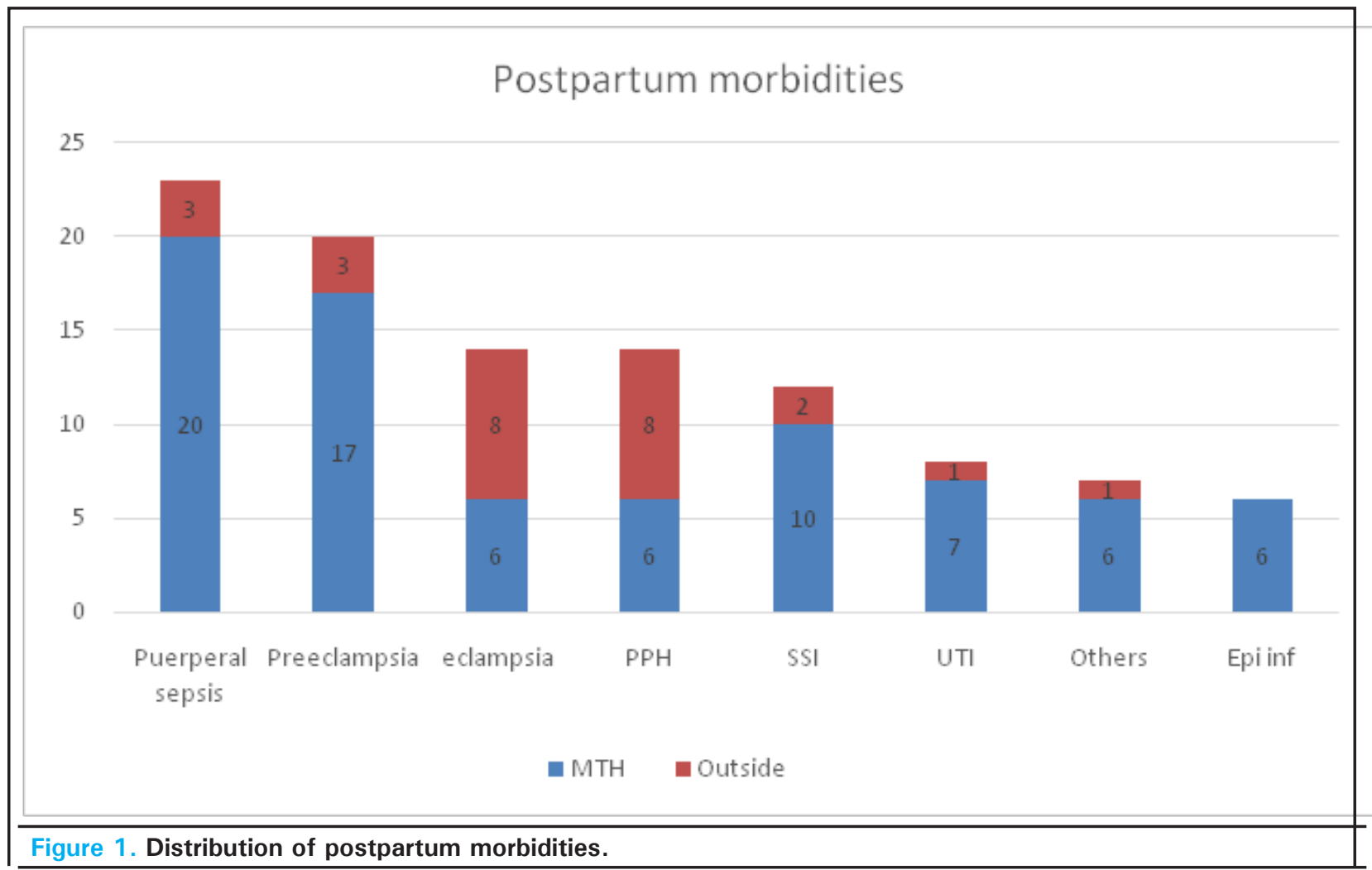

hospital and referred from other places has been shown (Figure 1).

Total obstetric admissions were 3510 during the study period of which $2988(85.13 \%)$ patients delivered at the study hospital. The prevalence of postpartum morbidity was 104 (2.96\%) among which 78 (75\%) patients had their delivery in the study hospital. Of these 78 patients, $27(34.62 \%)$ patients had vaginal delivery and 51 (65.39\%) had caesarean section.

\section{DISCUSSION}

The period after delivery represents a source of significant morbidity and mortality for women and their babies. In this study incidence of postpartum morbidity was $2.96 \%$ which was similar to the study done by Raut B, et al. $1.94 \%$ and Malla R, et al. $1.58 \% .^{4,7}$ The mean age in our study was 26.31 years which was similar to the study done by Malla $\mathrm{R}$, et al. with mean age of 26.7 years. $^{7}$

Among patients admitted with postpartum morbidities the duration of hospital stay was 2-7 days for $83.65 \%$ and $>7$ days for $16.34 \%$. The average duration of hospital stay was 5.98 days (range 2-18) which was similar to the study done by Raut $\mathrm{B}^{6}$ where $73.8 \%$ were admitted for 3-7 days and average duration of hospital stay was 4.53 days.

In this study puerperal sepsis was diagnosed in $22.11 \%$.
Pueperal sepsis was the most common complication in the study done by Vallely $\mathrm{L}$, et al. in Lusaka, Zambia $34.8 \% .{ }^{8}$ Hypertension and eclampsia accounts for $12 \%$ of maternal mortality. ${ }^{9}$ In our study, $19.23 \%$ women were admitted for preeclampsia and $13.46 \%$ with eclampsia. Women admitted with hypertensive disorder was higher in our study as compared to study done by Raut B $8.8 \% .^{4}$ The higher incidence of hypertensive disorder in our study could be due to the inclusion of patients who were referred from other centres as well. A study done by Rana $\mathrm{S}$, et al. showed approximately $15 \%$ of postpartum eclampsia. ${ }^{10}$ Ensuring a proper antenatal and postnatal care is important in seeking timely care which can reduce maternal mortality.

About $13.46 \%$ patients presented with postpartum haemorrhage in present study. Out of these 14 patients, 6 patients had surgical evacuation, 1 patient underwent hysterectomy for placenta accreta and others were managed conservatively. $28.57 \%$ required blood transfusion. Postpartum haemorrhage was found in $22.8 \%$ of women in the study done byTalie A, et al. ${ }^{11}$ This was similar to the study done by Malla $R$, et al. where women admitted with Postpartum Hemorrhage was $18.5 \% .^{7}$ Increased morbidity was reported with secondary postpartum haemorrhage in the study done by Hoveyda F, et al. where $63 \%$ required surgical evacuation and $17 \%$ blood transfusion. Secondary PPH may result in significant morbidity and deserves more attention. ${ }^{12}$ 
In this study eight patients $7.69 \%$ had urinary tract infection, three of them presented with retention of urine. In a study done by Ahnfeldt-Mollerup $\mathrm{P}$, et al. postpartum urinary retention had a reported incidence of $3 \% .^{13}$

Postpartum morbidity was higher in caesarean delivery as compared to vaginal delivery in patients delivered in the study hospital. This was similar to the study done by Lydon -Rochelle $\mathrm{M}$, et al. who reported higher readmissions especially due to infectious morbidities. ${ }^{14}$ Twelvepatients, $11.53 \%$ were admitted with wound infections in our study. Effective strategies in controlling peripartum infections should be an obstetric priority.

This study was cross sectional study done only in single institute so all the patients with postpartum morbidities might not be included. The result in this study may not show the true picture of the postpartum morbidities in this area.

\section{CONCLUSIONS}

The incidence of postpartum morbidity was found to be $2.96 \%$. Puerperal sepsis, preeclampsia, eclampsia and haemorrhage were the major complications requiring admissions. Ensuring proper postnatal care may contribute to reduction of postpartum maternal complications and help in decline of maternal mortality.

\section{Conflict of Interest: None}

\section{REFERENCES}

1. Malla DS, Giri K, Karki C, Chaudhary P. Achieving millennium development goals 4 and 5 in Nepal. Int J Gynaecol Obstet. 2011 Sep;118 suppl 2:60-8. [PubMed | Full $\underline{\text { Text }}$ | DOI]

2. Li XF, Fortney JA, Kotelchuck M, Glover LH. The postpartum period: the key to maternal mortality. International Journal of Gynecology \& Obstetrics. 1996 Jul 1; 54(1):1-0. [PubMed |

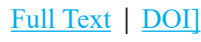

3. Measure DHS. Nepal Demographic and Health Survey 2011: Measure DHS, 2010. [Full Text]

4. Raut B. Readmissions for Morbidities among Women within the Puerperium. Journal of Universal College of Medical Sciences. 2015 Dec;3(4):10-5. [Full Text | DOI]

5. World Health Organization. Postpartum care of the mother and newborn: a practical guide: report of a technical working group. World Health Organization; 1998. [Full Text]

6. Sathian B, Sreedharan J, Banerjee I, Roy B. Simple sample size calculator for medical research: a necessary tool for the researchers. Medical Science. 2014;2(3):141-4. [․ㅏll Text | DOI]

7. Malla R, Manandhar R. Puerperal Morbidities After Delivery in a Tertiary Care Referral Hospital of Nepal. Medical Journal of Shree Birendra Hospital. 2016;15(2):8-12. [Full Text | DOI]

8. Vallely L, Ahmed Y, Murray SF. Postpartum maternal morbidity requiring hospital admission in Lusaka, Zambia-a descriptive study. BMC pregnancy and childbirth. 2005 Dec;5(1):1. [ull Text | DOI]

9. Lule E, Ramana GN, Ooman N, Epp J, Huntington D, Rosen JE. Achieving the millennium development goal of improving maternal health: determinants, interventions and challenges. Health nutrition and population discussion paper. 2005. [Full Text]

10. Rana S, Kattel P. Eclampsia at a tertiary care hospital of Nepal: A five year study. Janaki Medical College Journal of Medical Science. 2018 Dec; 6 (2):14-21. [Full Text | DOI]

11. Talie A, Yekoye A, Alemu M, Temesgen B, Aschale Y. Magnitude and associated factors of postpartum morbidity in public health institutions of Debre Markos town, North West Ethiopia. Matern Health Neonatol Perinatol. 2018 Dec; 4(1):19. [PubMed | Full Text | DOI]

12. Hoveyda F, MacKenzie IZ. Secondary postpartum haemorrhage: incidence, morbidity and current management. BJOG: an International Journal of Obstetrics \& Gynaecology. 2001 Sep;108(9):927-30. [․ㅏll Text | DOI]

13. Ahnfeldt-Mollerup P, Petersen LK, Kragstrup J, Christensen RD, Sorensen B. Postpartum infections: occurrence, healthcare contacts and association with breastfeeding. Acta Obstet Gynecol Scandivica. 2012 Dec; 91(12):1440-4. [Full Text I DOI]

14. Lydon-Rochelle M, Holt VL, Martin DP, Easterling TR. Association between method of delivery and maternal rehospitalization. JAMA. 2000 May; 283(18):2411-16. [Full $\underline{\text { Text }}$ | DOI]

The Author(s) 2018.

This work is licensed under a Creative Commons Attribution 4.0 International License. The images or other third party material in this article are included in the article's Creative Commons license, unless indicated otherwise in the credit line; if the material is not included under the Creative Commons license, users will need to obtain permission from the license holder to reproduce the material. To view a copy of this license, visit http://creativecommons.org/licenses/by/4.0/ 